\title{
Clonal lines of Salmonella enterica serotype Enteritidis documented by IS200-, ribo-, pulsed-field gel electrophoresis and RFLP typing
}

\author{
J. E. OLSEN, MARIANNE N. SKOV, E. J. THRELFALL* and D. J. BROWN \\ Department of Veterinary Microbiology, The Royal Veterinary and Agricultural University, Bülowsvej 13, \\ DK 1870 Frederiksberg C., Denmark and "Laboratory of Enteric Pathogens, Central Public Health Laboratory, \\ 61 Colindale Avenue, London NW9 5 HT
}

\begin{abstract}
Summary. Sixty-two selected strains of Salmonella serotype Enteritidis of 33 phage types (PTs), and one strain classified as RDNC, were characterised by four different chromosomally based typing methods to elucidate genetic relationships among strains of different phage types. Based on IS200-hybridisation patterns, two major groups, containing strains of the most commonly encountered phage types, and six minor groups (seven with the RDNC strain included) were observed. IS200 pattern was a stable epidemiological marker in strains of all phage types except PT 6a and 14b. Ribotyping separated strains of the phage types into one major and five minor groups; the pattern of the RDNC strain was not seen with other strains. More than one ribotype was observed among strains of Enteritidis PTs 6, 7, 14b and 21. By pulsed-field gel electrophoresis, strains of 21 of the 33 phage types formed one large cluster when bands $>125 \mathrm{~kb}$ were used as the criterion for separation. Among strains belonging to PTs 1, 6, 7 and 14b, more than one pattern was observed by this method. By probing with five random cloned fragments of the Enteritidis chromosome, strains from 27 of 31 phage types examined showed the same hybridisation pattern. With the combined use of four genotypic methods, two groups of strains, representing eight and seven of 33 Enteritidis phage types, were formed; these two groups may be considered as the main evolutionary lines of Enteritidis. Strains of the remaining phage types, and the RDNC strain, belonged to separate groups.
\end{abstract}

\section{Introduction}

Salmonella enterica serotype Enteritidis $(S$. Enteritidis) is a common cause of foodborne gastroenteritis and the incidence of human salmonellosis caused by strains of this serotype has increased dramatically in many European countries. ${ }^{1}$ For epidemiological investigations, Enteritidis can be subdivided by phage typing ${ }^{2}$ and currently 44 different phage types (PTs) have been identified. ${ }^{3}$ Some of these PTs can be further subdivided by plasmid profiling. ${ }^{4}$

Strains of most serotypes of Salmonella contain copies of a 708-bp long, Salmonella-specific, insertion element IS $200 ;^{5-7}$ the function is essentially unknown, ${ }^{8}$ but it seems to insert evenly into different regions of the chromosome. ${ }^{9}$ Based on the copy number of IS200 and the fragments into which it has inserted, Stanley $e t$ al. ${ }^{10}$ grouped Enteritidis strains of different PTs into three evolutionary lines. The patterns obtained for strains within a phage type are stable, ${ }^{11,12}$ and all epidemic strains from the UK have been shown to carry the same IS200 pattern. ${ }^{11}$ Therefore, it was concluded that the present epidemic of Enteritidis PT 4 is caused by a single clonal line of bacteria, a suggestion supported by results from other typing methods. ${ }^{13}$

Ribotyping, ${ }^{14}$ pulsed-field gel electrophoresis (PFGE) ${ }^{15}$ and restriction fragment-length polymorphisms (RFLPs) ${ }^{\mathbf{1 6}}$ have also been used to study the phylogeny of bacterial species. Results from IS200-probing and from these other three methods used in parallel may enable a more thorough subdivision of Enteritidis and, at the same time, serve to evaluate results obtained previously from IS200 typing alone.

In the present investigation, type strains of Enteritidis of different PTs ${ }^{2}$ together with a collection of human clinical and poultry isolates from Denmark have been characterised by IS200-typing, ribotyping, PFGE and RFLP. The results have been analysed both in terms of their phylogenetic significance and their applicability to the epidemiology of Salmonella. 
Table I. Bacterial strains used

\begin{tabular}{|c|c|c|c|}
\hline $\begin{array}{l}\text { Phage } \\
\text { type (PT) }\end{array}$ & Type strain* & $\begin{array}{c}\text { Clonal } \\
\text { line } †\end{array}$ & $\begin{array}{c}\text { Number of } \\
\text { additional } \\
\text { strains+ }\end{array}$ \\
\hline 1 & E2331 & I & 4 \\
\hline 2 & E2457 & II & 1 \\
\hline 3 & P66040 & I & 0 \\
\hline 4 & E2187 & I & 5 \\
\hline $4 a$ & P99764 & I & 0 \\
\hline 5 & P70001 & I & 0 \\
\hline 6 & P99327 & I & 4 \\
\hline $6 a$ & E2408 & II & 1 \\
\hline 7 & E1492 & I & 4 \\
\hline 8 & E2468 & II & 5 \\
\hline 9 & $\mathrm{E} 2402$ & I & 0 \\
\hline $9 b$ & NI & - & 1 \\
\hline 10 & E3945 & II & 0 \\
\hline 11 & E2109 & III & 0 \\
\hline 12 & P95661 & I & 0 \\
\hline 13 & E464 & II & 2 \\
\hline $13 a$ & NI & - & 1 \\
\hline 14 & E2387 & III & 0 \\
\hline $14 \mathrm{~b}$ & NI & - & 2 \\
\hline 15 & E2407 & III & 0 \\
\hline 16 & E866 & - & 0 \\
\hline 17 & P95940 & I & 0 \\
\hline 18 & P89448 & III & 0 \\
\hline 19 & E1949 & I & 0 \\
\hline 20 & P68147 & III & 0 \\
\hline $20 \mathrm{a}$ & NI & - & 1 \\
\hline 21 & P72580 & I & 1 \\
\hline 22 & P84357 & II & 0 \\
\hline 23 & P88255 & II & 0 \\
\hline 24 & P99768 & II & 0 \\
\hline 25 & P100613 & I & 0 \\
\hline 31 & NI & - & 1 \\
\hline 32 & NI & - & 2 \\
\hline RDNC & - & - & 1 \\
\hline
\end{tabular}

NI, the type strain was not included.

RDNC, the type strain reacted with the typing phages but lytic patterns did not correspond to any recognised phage type.

* The characteristics of the type strains, kindly provided by $\mathrm{Dr} B$. Rowe, LEP, Central Public Health Laboratory, London, have been described elsewhere. ${ }^{2,4}$

$\dagger$ Allocation of strains to "clonal lines" of Enteritidis was based on IS 200 patterns $;{ }^{10}$ strain E866 could not be so assigned. ${ }^{10}$

\$ Strains from man and poultry in Denmark. ${ }^{17}$

\section{Materials and methods}

\section{Bacterial strains, media and culture conditions}

Enteritidis strains, listed in table I, were stored in sterile glycerol $15 \% \mathrm{v} / \mathrm{v}$ at $-80^{\circ} \mathrm{C}$ and grown overnight in LB broth or on LB agar plates ${ }^{18}$ at $37^{\circ} \mathrm{C}$.

\section{Southern analysis}

Total DNA was isolated as described by Christensen et al. ${ }^{19}$ Approximately $1 \mu \mathrm{g}$ was digested with $P v u \mathrm{II}$ (IS200), Pst (IS200 and RFLP) or SmaI (ribotyping) (all from Boehringer Mannheim). DNA was transferred to Hybond-N hybridisation membranes (Amersham) by vacuum blotting and hybridised with 11-dUTP-digoxigenin (Boehringer Mannheim)labelled probes as described previously. ${ }^{20}$ Plasmid DNA was isolated and analysed by agarose-gel electrophoresis (AGE) as before. ${ }^{20}$

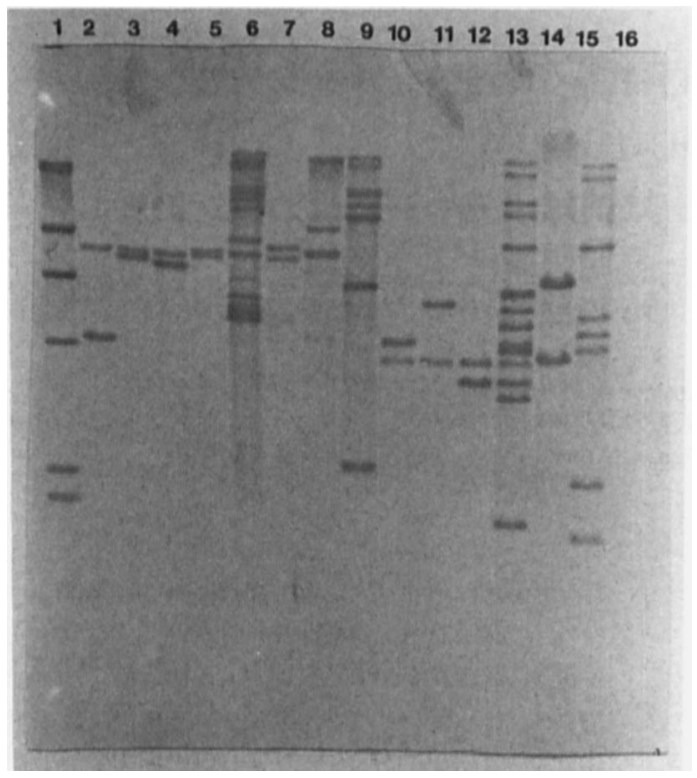

Fig. 1. Patterns observed among Enteritidis strains after hybridisation with insertion element IS200. Lane 1, HindIII-digested $\lambda$ DNA as size marker. Lanes $\mathbf{2 - 9}$, patterns after digestion with PvuII; 2, type I (PT 1); 3, type II (PT 2); 4, type III (PT 11); 5, type IV (PT 14); 6, type V (PT 16); 7, type VI (PT 18); 8, type VII (PT 14b); 9, type VIII (RDNC). Lanes 10-15, patterns after digestion with PstI : 10, type I (PT 1); 11, type II (PT 2); 12, type IV (PT 11); 13, type V (PT 16); 14, type III (PT 9b); 15, type VI (RDNC).

\section{IS200}

Plasmid pIZ45, containing a 300-bp internal fragment of insertion element IS $200,{ }^{6}$ was kindly provided by Dr J. Casadesús, Department of Genetics, University of Seville, Spain. The fragment was excised after digestion with EcoRI-HindIII and re-cloned in vector pGEM3 (Scandinavian Diagnostic Systems) by standard cloning techniques. ${ }^{18}$

For use as a hybridisation probe, vector-free IS200 was generated by polymerase chain reaction (PCR) with oligonucleotides complementary to 26 and 25 bases of the promotor sequences T7 and SP6, as primers. PCR assay conditions have been described. ${ }^{21}$ Generated PCR product was subjected to AGE in agarose (Litex LSL) $1.2 \% \mathrm{w} / \mathrm{v}$ in $1 \times \mathrm{TAE}^{\text {T }}$ uffer ${ }^{18}$ and purified with a DNA-isolation kit (Prep-a-Gene, BioRad). IS200 probe was labelled with digoxigenin by random priming. ${ }^{22}$

\section{Ribosomal RNA probe}

Ribosomal RNA from Escherichia coli (Sigma) was purchased and labelled with digoxigenin by use of reverse transcriptase (Boehringer Mannheim), as described by Christensen et al. ${ }^{19}$

\section{Random cloned DNA probes}

Chromosomal DNA from strain P132344/123 of Enteritidis PT 4 was digested with EcoRI and HindIII; resulting fragments were cloned in $E$. coli strain 
Table II. Grouping of Enteritidis strains by IS200 type, ribotype, PFGE and RFLP

\begin{tabular}{|c|c|c|c|c|c|c|c|}
\hline \multirow{2}{*}{$\begin{array}{l}\text { Phage } \\
\text { type } \\
\text { (PT) }\end{array}$} & \multicolumn{3}{|c|}{ IS-200type* } & \multirow{2}{*}{$\begin{array}{l}\text { Ribotype } \\
\text { SmaI }\end{array}$} & \multicolumn{2}{|c|}{$\begin{array}{l}\text { NotI PFGE-type } \\
\text { bands }\end{array}$} & \multirow{2}{*}{$\begin{array}{r}\text { RFLF } \\
\text { PstI }\end{array}$} \\
\hline & PvuII & $p_{s t \mathrm{I}}$ & Combined & & All & $>150 \mathrm{~kb}$ & \\
\hline 1 & I & I & I & I & $\mathrm{I}^{\dagger}$ & $\mathrm{I} \dagger$ & I \\
\hline 2 & II & II & II & II & II & I & I \\
\hline 3 & I & I & I & III & III & I & II \\
\hline 4 & I & I & I & II & IV & I & I \\
\hline $4 a$ & I & I & I & II & IV & I & I \\
\hline 5 & I & I & I & I & $\mathrm{V}$ & II & I \\
\hline 6 & I & I & I & II $\dagger$ & $\mathrm{VI} \dagger$ & $\mathrm{I} \dagger$ & I \\
\hline $6 \mathrm{a} \ddagger$ & I & I & $\mathrm{I}^{\dagger}$ & I & VI & I & I \\
\hline 7 & I & I & I & $\mathrm{II} \dagger$ & VIIt & $\mathrm{I}^{+}$ & I \\
\hline 8 & II & II & II & II & $\mathrm{II} \dagger$ & I & I \\
\hline 9 & I & I & I & II & VIII & III & I \\
\hline $9 b$ & I & III & III & II & IX & IV & I \\
\hline 10 & II & II & II & III & II & I & I \\
\hline 11 & III & IV & $\mathrm{V}$ & I & $\mathrm{X}$ & $\mathrm{V}$ & I \\
\hline 12 & I & I & I & II & XI & VI & I \\
\hline 13 & II & II & II & II & IV & I & I \\
\hline $13 a$ & II & II & II & II & II & I & ND \\
\hline 14 & IV & IV & VI & IV & XII & VII & III \\
\hline $14 \mathrm{~b}$ & II/VII & IV & VII/VIII & V/VI & XIII/XIV & VIII/IX & ND \\
\hline 15 & IV & IV & VI & I & I & I & I \\
\hline 16 & $\mathrm{~V}$ & $\mathrm{~V}$ & IX & VII & $X V$ & $\mathrm{X}$ & IV \\
\hline 17 & I & I & I & II & $\mathrm{XI}$ & VI & I \\
\hline 18 & VI & IV & $\mathrm{X}$ & II & XI & VI & I \\
\hline 19 & I & I & I & III & III & I & II \\
\hline 20 & III & IV & $\mathrm{V}$ & I & $\mathrm{X}$ & $\mathrm{V}$ & I \\
\hline $20 \mathrm{a}$ & I & I & I & I & I & I & I \\
\hline 21 & I & I & I & $\mathrm{II} \dagger$ & IV & I & I \\
\hline 22 & II & II & II & II & II & I & I \\
\hline 23 & II & II & II & II & II & I & I \\
\hline 24 & II & II & II & II & II & I & I \\
\hline 25 & I & I & I & II & IV & I & I \\
\hline 31 & I & I & I & II & IV & I & I \\
\hline 32 & I & I & I & I & I & I & I \\
\hline RDNC & VIII & VI & XI & VIII & XVI & XI & ND \\
\hline
\end{tabular}

ND, not done.

* Roman numbers assigned arbitrarily to each pattern demonstrated. The pattern of the type strain only is given but, if type strains were not included, all observed patterns of other strains of PT are listed.

$\dagger$ Of additional strains tested, $\geqslant 1$ had patterns different from that of type strain by stated method.

$\ddagger$ An extra, plasmid-carried copy of IS 200 was present in the type strain of this PT.

$\mathrm{HB} 101^{18}$ with $\mathrm{pBR} 322$ or pGEM3 as vectors. Five DNA fragments, fSE4 $(1.7 \mathrm{~kb})$, fSE5 $(6 \mathrm{~kb})$, fSE6 $(2 \cdot 1 \mathrm{~kb})$, fSE9 $(2 \cdot 5 \mathrm{~kb})$ and fSE10 $(5 \mathrm{~kb})$ were propagated, digested with EcoRI/HindIII, and separated from the vector by AGE. Fragments were purified and labelled as described above.

\section{Pulsed-field gel electrophoresis}

Strains were grown overnight on LB agar at $37^{\circ} \mathrm{C}$ and three or four colonies were inoculated into LB broth and incubated at $37^{\circ} \mathrm{C}$ until an $\mathrm{OD}_{600}$ value of $c$. 0.1 was reached. Genomic DNA was prepared in lowgelling point agarose (BioRad) by a procedure developed at the Centers for Disease Control, Atlanta, GA USA (Dr D. N. Cameron, personal communication). Briefly, cells were embedded in agarose, lysed with lysozyme (Boehringer Mannheim) $0.1 \mathrm{mg} / \mathrm{ml}$, sarcosyl (Sigma) 0.05\% w/v and sodium deoxycholate (Sigma) $0.02 \% \mathrm{w} / \mathrm{v}$, treated with proteinase $\mathrm{K}$
(Boehringer Mannheim), rinsed with $\mathrm{dH}_{2} \mathrm{O}$ and treated twice with TE containing $15 \mu \mathrm{l} / \mathrm{ml}$ of a solution of phenyl-methyl-sulphonyl fluoride (Sigma) $17 \mathrm{mg} / \mathrm{ml}$ in isopropanol (Merck). After rinsing with $\mathrm{TE}$, the agarose plug was ready for use in restriction analysis. Slices of agarose blocks containing DNA were digested for $4 \mathrm{~h}$ with $20 \mathrm{U}$ of NotI (Boehringer Mannheim or Amersham).

DNA fragments were subjected to AGE in agarose (Litex LSL) $1 \% \mathrm{w} / \mathrm{v}$ in $0.5 \times \mathrm{TBE}$ buffer $^{18}$ in a contour-clamped homogeneous electric field (CHEF) system (Pulsaphor Plus, Pharmacia LKB). The running conditions were $12 \mathrm{~V} / \mathrm{cm}$ at $14^{\circ} \mathrm{C}$ for $22 \mathrm{~h}$. Pulse times were increased by stepping, as follows: $2 \mathrm{~s}$ in $5 \mathrm{~h}$, $5 \mathrm{~s}$ in $6 \mathrm{~h}, 9 \mathrm{~s}$ in $6 \mathrm{~h}$ and $12 \mathrm{~s}$ in $5 \mathrm{~h}$. Polymerised phage$\lambda$ DNA (Pharmacia LKB) was used as molecular-size marker. After electrophoresis, the gels were stained in aqueous ethidium bromide (Sigma) $2 \mu \mathrm{g} / \mathrm{ml}$ for $15 \mathrm{~min}$, destained in distilled water for $15 \mathrm{~min}$ and photographed under 254-nm UV-light. 


\section{Results}

\section{Probing with IS200}

Total DNA preparations from type strains of 27 different PTs of Enteritidis and strains belonging to additional PTs were digested with PvuII and PstI and

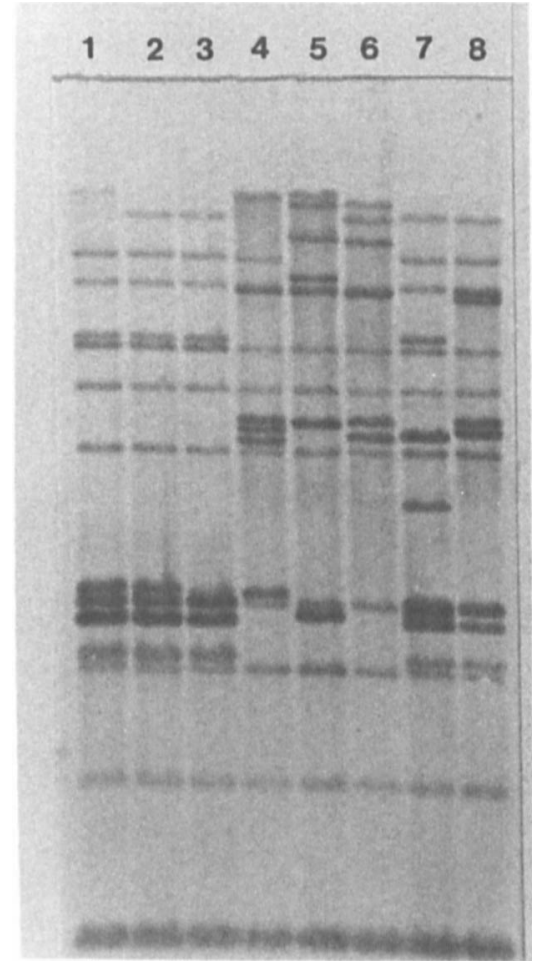

Fig. 2. SmaI ribotypes observed among Enteritidis strains: lane 1, type I (PT 1); 2 , type 2 (PT 2); 3, type 3 (PT 3); 4, type IV (PT 14); 5 , type VII (PT 16); 6, type VIII (RDNC); 7, type V (PT 14b); 8, type VI (PT 14b).

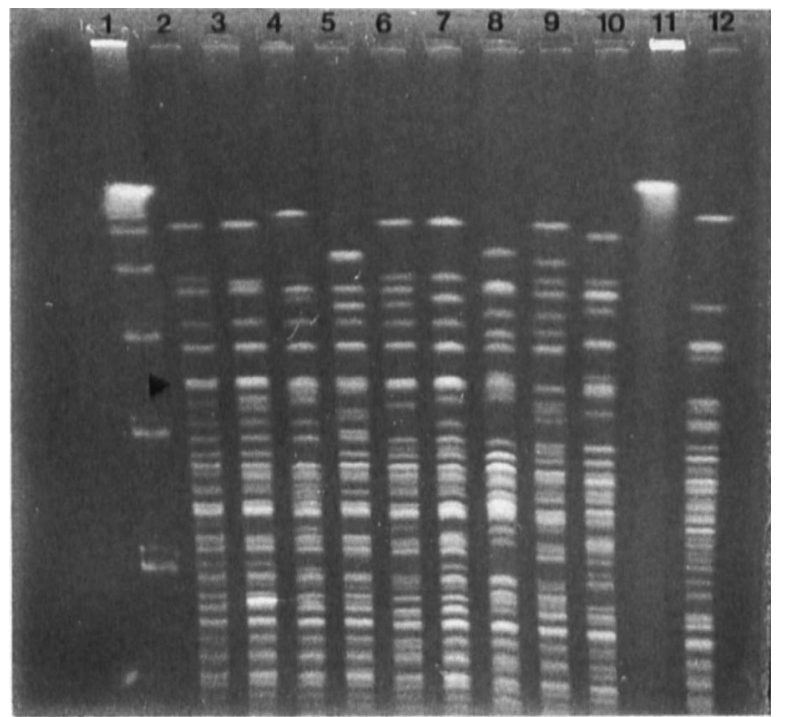

Fig. 3. PFGE patterns observed among Enteritidis strains after DNA digestion with NotI. Lane 1 , multimers of phage $\lambda(48.5 \mathrm{~kb})$ as molecular-size marker; PFGE patterns are: lane 2, I (PT 3); 3, II (PT 5); 4, III (PT 9); 5, IV (PT 9b); 6, V (PT 11); 7, VI (PT 12); 8, VII (PT 14); 9, VIII (PT 14b); 10, IX (PT 14b); 11, X (PT 16, which is not cut by $N o t \mathrm{I}) ; 12$, XI (RDNC strain). Only bands larger than indicated by arrow were used to group strains according to PFGE

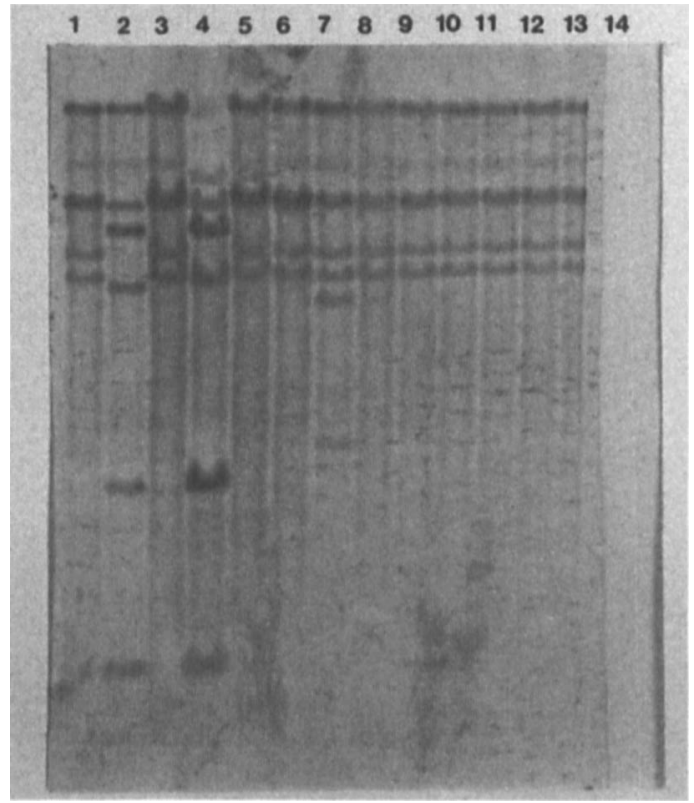

Fig. 4. RFLP patterns observed among PstI-digested DNA of type strains of Enteritidis after probing with five random cloned fragments of Enteritidis chromosome. RFLP patterns are: lane 1, I (PT 13); 2, III (PT 14); 3, I (PT 15); 4, IV (PT 16); 5 and 6, pattern I (PTs 17 and 18); 7, II (PT 19). RFLP pattern $V$ demonstrated in a strain of PT RDNC is not shown.

probed with IS200; as shown in fig. 1, eight and six different restriction patterns, respectively, were demonstrated with these two restriction enzymes. The patterns observed with strains from different PTs are listed in table II. Strains from 17 of the PTs belonged to the most common type when both enzymes were used for grouping; two Enteritidis strains of PT14b tested had different patterns. Enteritidis strains were usually found to contain two copies of IS200 whereas the type strain of PT 6a contained three copies; the extra copy, which by Southern analysis was shown to be inserted into a plasmid, was not present in another strain of PT 6a tested. The type strain of PT 16 had at least 15 copies in the genome, just as the Enteritidis strain of PT RDNC contained at least eight copies (fig. 1).

\section{Ribotyping}

When SmaI-digested DNA was probed with $16 \mathrm{~S}$ and 23S cDNA, eight different ribotypes were observed (fig. 2). As seen in table II, strains from 19 of the PTs tested had the same SmaI ribotype. In one Enteritidis strain of PT 6, two strains of PT 7 and one strain of PT 21, the observed ribotype did not correspond to that of the type strain. Two strains of Enteritidis PT $14 \mathrm{~b}$ had different ribotypes.

\section{Pulsed-field gel electrophoresis (PFGE)}

As shown in table II, the result of typing by PFGE was scored in two ways. If all bands were considered, 15 different restriction patterns could be distinguished. DNA from Enteritidis PT 16 was not cut by NotI. To 


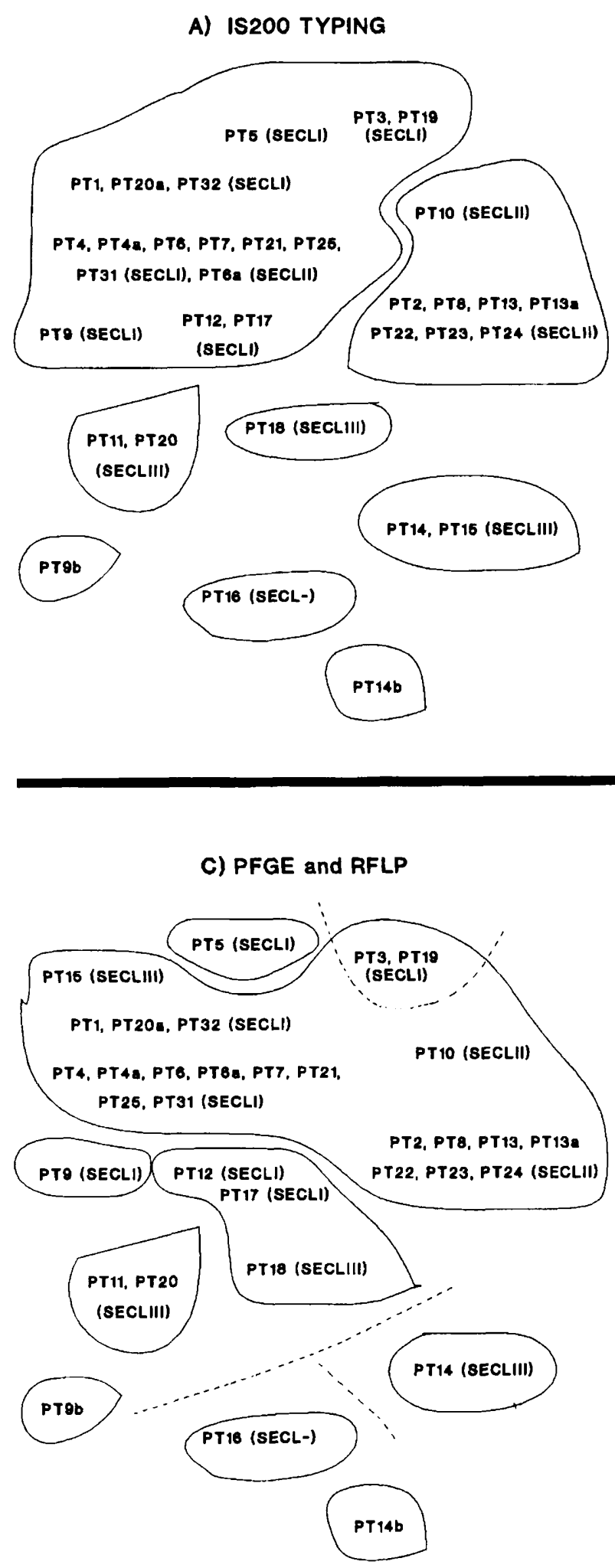

B) Ribotyping

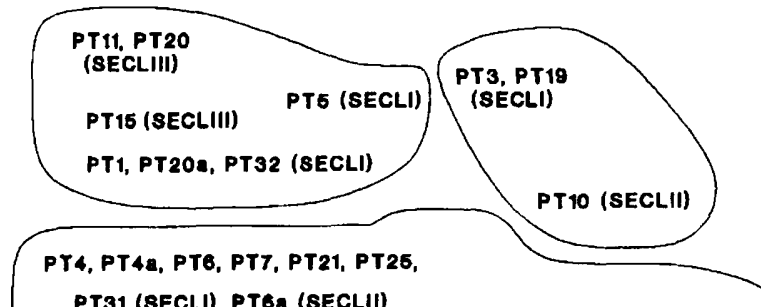

PT31 (sECLI). PTEa (SECLII)

PTO (SECLI)
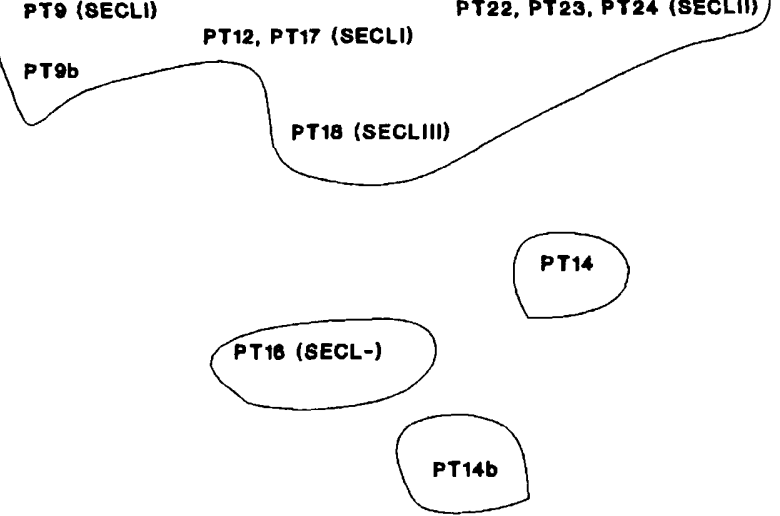

D) Combined use of 4 typing methods

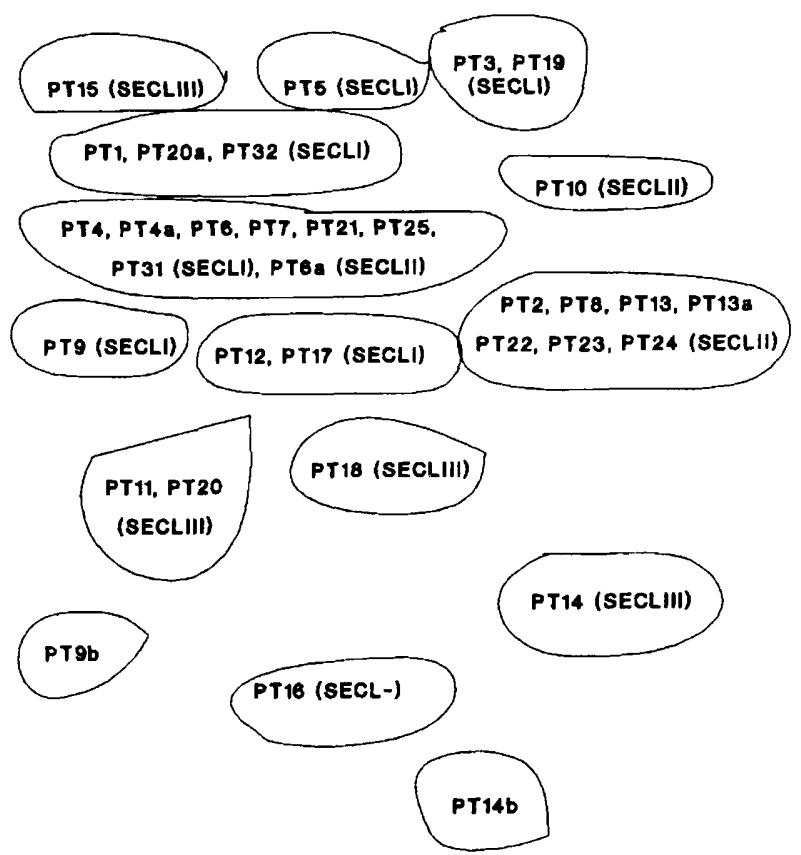

Fig. 5. Grouping of strains from 33 PTs of Enteritidis according to four different chromosomal typing methods: A, IS200 typing; B, ribotyping; C, PFGE and RFLP; D, all four typing methods together. PTs for which all strains showed the same characters are enclosed in a circle. RFLP separation of strains is shown by a dotted line in part C. Throughout the figure, the strains are listed by PT and "clonal line" $(\mathrm{SECL})^{10}$. NB, individual PTs in most cases are in the same positions in all four parts of the figure. The RDNC strain examined has been omitted from the figure but, by all four criteria for grouping, would have formed its own group.

make PFGE comparable with other typing methods, the possible interference of plasmid bands was avoided by scoring only those bands $>125 \mathrm{~kb}$. The different types observed among Enteritidis strains by this method are shown (fig. 3). A total of 10 different patterns, in addition to the uncut DNA from Enteritidis PT 16, was observed by this method, and the most common pattern was demonstrated with 
strains from 22 of the PTs (table II). For one strain each of Enteritidis PTs 1, 6, and 7, PFGE patterns differed from that of the type strain. Two Enteritidis strains of PT 14b had different PFGE patterns.

\section{Random cloned chromosomal probes (RFLP)}

As seen in fig. 4, four different restriction patterns were observed when five chromosomal fragments were hybridised to PstI-digested DNA from strains representing 31 of the 33 PTs. The patterns observed with strains of different PTs are listed (table II). Strains from 27 of the 31 PTs tested showed the same pattern.

\section{Grouping based on all four typing methods}

Grouping of Enteritidis strains of different PTs by each method used alone or in combination is shown (fig. 5). Two groups of strains of eight and seven PTs were formed: (i) Enteritidis strains of PTs 4, 4a, 6, 6a, 7, 21, 25 and 31; and (ii) PTs 2, 8, 13, 13a, 22, 23 and 24. Another four minor groups were also formed: Enteritidis strains of PTs 1, 20a and 32; PTs 11 and 20; PTs 3 and 19; and PTs 12 and 17. The remaining PTs could not be allocated to any of these groups based on reactions from all four typing methods.

\section{Discussion}

Based on RFLP with insertion element IS200, Enteritidis $^{10-12}$ and other Salmonella serotypes ${ }^{24-26}$ have been grouped into "clonal lines". A similar RFLP method, based on insertion element IS6110, has been used with Mycobacterium tuberculosis. ${ }^{27}$

The IS200 patterns of the type strains of 21 different Enteritidis PTs, belonging to Enteritidis clonal lines (SECL) I and $\mathrm{II}^{10}{ }^{10}$ were confirmed in the present investigation. Like Stanley et al. ${ }^{10}$ we detected three copies of IS200 in the type strain of Enteritidis PT 6a. The extra copy, which is carried on a plasmid, ${ }^{10}$ (and this investigation), was absent from an additional strain of PT 6a tested. Based on the remaining bands, which were the same in both strains of that PT, strains of Enteritidis PT 6a were allocated to IS200-SECLI, not SECLII as described by Stanley et al. ${ }^{10}$

Strains from several PTs not previously typed by IS200 were included in the present investigation. Of these, Enteritidis strains of PTs 20a, 31 and 32 belonged to IS200-SECLI and of PT 13a belonged to IS200-SECLII. IS200-SECLIII (see table I) in our study contained three different patterns; the type strains of the PTs included in SECLIII were also shown to be diverse by other genomic typing methods. In our opinion, IS200-SECLIII of Stanley et al. ${ }^{10}$ cannot be regarded as a "clonal line".

IS200-type has usually been stable in strains within phage types of Enteritidis; ${ }^{10,11}$ in the present investigation, however, that was not true for Enteritidis strains of PTs $6 a$ and 14b. In PT 6a, divergence was due to a plasmid-encoded band in the type strain; two strains of PT 14b were different by IS200-, ribo- and PFGE typing, and it seems likely that this PT contains strains of more than one "clonal line". Thus, all typing methods could be used to subdivide strains of PT $14 \mathrm{~b}$.

In serotype Heidelberg, one "IS200 clonal line" is mainly associated with human infections whilst another is dominant among chicken isolates. ${ }^{25} \mathrm{~A}$ corresponding relationship between IS200 patterns and "clonal lines" has not yet been demonstrated for Enteritidis. However, other genotypic typing methods, such as ribotyping, PFGE and RFLP, may be used to support results obtained by IS200-typing.

In this study, only SmaI was used for ribotyping. In comparison with other enzymes, SmaI has been preferred previously for subdivision of Salmonella serotypes Berta and Enteritidis, ${ }^{\mathbf{2 0}, 28}$ whilst it was of medium discriminatory power in Typhi. ${ }^{29}$ Other enzymes may be more discriminatory; for example, $H$ indIII has been preferred for Gallinarum ${ }^{19}$ and ClaI for Typhi. ${ }^{30}$

Ribotyping gave much the same degree of discrimination as IS200, but, as shown in fig. 5, it grouped Enteritidis strains differently. For Enteritidis strains of PTs $6,7,14 \mathrm{~b}$ and 21 , more than one ribotype was observed, and for epidemiological purposes, SmaI ribotypes may be used to discriminate further among strains of these PTs. The present data do not disclose whether PT or ribotype is the best evolutionary indicator; however, the fact that strains of several PTs have the same ribotype makes the latter more likely. It seems also that PT is subject to convergence by external factors, as the introduction of inc $N$ plasmids has been shown to change the lytic pattern of a number of Enteritidis PTs. ${ }^{31,32}$

In a number of cases, such as enterohaemorrhagic E. coli and pathogenic Leptospira, PFGE has subdivided the bacteria into biologically meaningful subgroups, ${ }^{33,34}$ and so the method was included in this investigation. PFGE was the most discriminatory of the genomic typing method for Enteritidis, when all restriction fragments were used to group strains. As has been reported for a number of other bacteria, e.g., Staphylococcus spp. ${ }^{35}$ Legionella pneumophila ${ }^{36}$ and Campylobacter hyointestinalis, ${ }^{37} \mathrm{PFGE}$ is of potential use for outbreak investigations, used alone or together with less stable markers such as plasmid profiles and antibiotic resistance.

To exclude restriction polymorphism due to plasmid DNA, only DNA fragments $>125 \mathrm{~kb}$ were used for grouping of strains of PTs. Thus, strains within groups shared a minimum of five to eight large bands, but sometimes differed in smaller bands, some of which may have been of plasmid origin.

In essence, PFGE with this scoring method united strains from 22 of the $33 \mathrm{PTs}$ in a single cluster. Of the PTs in IS200-SECLI and SECLII, ${ }^{10}$ only strains from PTs 5, 9, 12 and 17 had PFGE patterns different from the main cluster. By IS200-, ribo- and RFLP-typing, 
however, strains of these phage types grouped in the main cluster(s) and we suspect that, until relatively recently in evolutionary terms, they belonged to the main PFGE group. Unique PFGE patterns were observed in additional Enteritidis strains of PTs 1, 6 and 7 and, even when only bands $>125 \mathrm{~kb}$ are scored, PFGE may be used to discriminate among these phage types. For unknown reasons, NotI was found not to cut DNA from Enteritidis PT 16. The same DNA preparations could be digested with $S m a \mathrm{I}$ or $\mathrm{XbaI}$ (data not shown); it may be that strains of PT 16 contain a modification system protecting against $N o t \mathrm{I}$.

Like PFGE, RFLP does not cover a particular part of the chromosome. Tompkins et al. ${ }^{16}$ described RFLP as a potential epidemiological tool, since most unrelated strains of Typhimurium showed unique patterns when probed with random cloned fragments. However, the five fragments used in the present investigation seem to cover conserved parts of the chromosome, as all but four of the Enteritidis strains tested showed the same pattern. Of these, strains of PTs 3 and 19 belonged to the main IS200-, ribotype and PFGE groups, and in all methods showed the same patterns. The RFLP result underlines the close genomic relationship between Enteritidis strains of PTs 3 and 19 and, based on the results in other typing methods, the two PTs should still be considered close to the main group of Enteritidis.

The most detailed picture of relationships among Enteritidis strains of different PTs is provided by the combined use of all four typing methods. As illustrated in fig. 5, IS200-SECLI of Stanley et al. ${ }^{10}$ could be divided into one group containing Enteritidis strains of eight PTs with PT 4 the most prominent member; a second containing strains of three PTs with PT 1 as a prominent member; another two groups each of two PTs; and two separate PTs. IS200-SECLII ${ }^{10}$ was intact with the exception of Enteritidis PTs 6a and 10. PT 13a was included in this clonal line, which then contains the predominant PTs among poultry in the USA and Canada. ${ }^{38}$ The reason for the dominance in these countries of SECLII rather than the PTs of SECLI is unknown, but the fact that two different "clonal lines" are dominant on different continents may be considered to support the division of Enteritidis into "clonal lines" by our methods.

The relationships among strains of PTs in SECLI and SECLII and the remaining Enteritidis PTs (i.e., PTs 9b, 11, 14, 14b, 15, 16, 18 and 20) were less clear. The type strains of Enteritidis PTs 11 and 20 grouped together, and as with Enteritidis PT 15, they were linked to PTs 1, 5, 20a and 32 by ribotype. Enteritidis PT 18, which was grouped in the IS200-SECLIII by Stanley et al. ${ }^{10}$ was related to PTs 12 and 17 by PFGE and to a number of PTs by the SmaI ribotype.

The only isolate of Enteritidis PT 9b tested was linked to the main group of Enteritidis by ribotype and RFLP, whilst strains of Enteritidis PTs 14, 14b and 16 had unique patterns by all, or all but one, of the methods used. This finding may indicate that strains of these PTs diverged early from those of other Enteritidis PTs, or that they were created by larger mutational events. The latter explanation might be true for the Enteritidis strains of PT 16 and RDNC that contain numbers of IS200 elements higher than normal for Enteritidis.

The data presented do not disclose how the events that led to different IS200-, ribo-, PFGE- and RFLPtypes relate to each other in time. One possible interpretation is that PFGE and RFLP, which identify similar groupings and put strains of most PTs into one cluster, reflect the most ancient picture of phage-type relationships. By mutations and IS200 insertions into these ancestral strains, a number of ribo-, IS200- and PTs have developed since; the more distant that two PT groups have become, the earlier they must have diverged.

There is only limited biological evidence to support the phylogenetic conclusion. Strains of Enteritidis PT 4 converts to PT 7 by loss of LPS $;{ }^{39}$ these two PTs were grouped together by all four typing methods. It was noted, however, that strains of Enteritidis PT 7 had more than one ribo- and PFGE type, and the biological relationships between Enteritidis PTs 4 and 7 may not be valid for all strains. As mentioned, a number of Enteritidis PTs can converge by the introduction of $i n c N$ plasmids: Enteritidis PTs 4 to 24, 7 to 23,8 to 24 , and 30 to untypeable, whilst PTs 13 and 13a do not change PT upon introduction of these plasmids. ${ }^{31,32}$ This convergence seems to occur between PTs which, in the present investigation, had the same $S m a$ I ribotype, the same Not $\mathrm{I}$ PFGE pattern and the same PstI RFLP pattern, whereas, for example, strains of Enteritidis PTs 4 and 24, like PTs 7 and 23, belonged to two different IS200-SECLs. Unless the introduction of the incN plasmids provokes a rearrangement of IS200 elements, this observation calls into question the stability of the phage-typing system or of the IS200 pattern for epidemiological investigations, and there is a need to look more carefully into this matter.

The way in which IS200 and ribotyping crossdivided the PTs might mean that the chromosome behaves, not as one molecule, but as a number of subunits where evolution takes place at different rates. When Enteritidis strains of two PTs have the same IS200 pattern but different ribotype, or vice versa, the same IS200 insertion or the same ribotype mutation must have occurred independently in different clonal lines indicating that either IS200-insertion or mutations in rRNA genes, or both, are non-random events. Regardless, the observation of the same IS200 type in different ribotypes calls for the use of both typing methods in parallel when performing phylogenetic or epidemiological studies.

This study was supported by The National Veterinary and Agricultural Research Council (Grant Nos. 13-4322 and 13-4538-1). We are grateful to Gitte Christensen, Susanne Rasmussen and Pia R. Mortensen for skilful technical assistance. We thank Dr Dorte Lau Baggesen of the National Veterinary Laboratory for phagetyping control of the strains used in this investigation; Dr Ørjan 
Olsvik, CDC, Atlanta, GA for help with setting up the pulsed-field gel electrophoresis system; Dr B. Rowe Central Public Health
Laboratory, for providing the Enteritidis phage-type strains, and $\mathrm{Dr}$ J. Casadesús for providing pIZ45 plasmid.

\section{References}

1. Rodrigue DC, Tauxe RV, Rowe B. International increase in Salmonella enteritidis: a new pandemic? Epidemiol Infect 1990; 105: 21-27.

2. Ward LR, de Sa JDH, Rowe B. A phage-typing scheme for Salmonella enteritidis. Epidemiol Infect 1987; 99: 291-294.

3. Threlfall EJ, Chart $\mathbf{H}$. Interrelationships between phage types of S. enteritidis. Epidemiol Infect 1993; 111: 1-8.

4. Threlfall EJ, Rowe B, Ward LR. Subdivision of Salmonella enteritidis phage types by plasmid profile typing. Epidemiol Infect 1989; 102: 459-465.

5. Lam S, Roth JR. IS200: a Salmonella-specific insertion sequence. Cell 1983; 34: 951-960.

6. Gibert I, Barbé J, Casadesús J. Distribution of insertion sequence IS200 in Salmonella and Shigella. J Gen Microbiol 136: 2555-2560.

7. Gibert I, Carroll K, Hillyard DR, Barbé J, Casadesús J. IS200 is not a member of the IS600 family of insertion sequences. Nucleic Acids Res 1991; 19 : 1343.

8. Lam S, Roth JR. Structural and functional studies of insertion element IS200. $J$ Mol Biol 1986; 187: 157-167.

9. Lam S, Roth JR. Genetic mapping of IS200 copies in Salmonella typhimurium strain LT2. Genetics $1983 ; 105$ : 801-811.

10. Stanley J, Jones CS, Threlfall EJ. Evolutionary lines among Salmonella enteritidis phage types are identified by insertion sequence IS200 distribution. FEMS Microbiol Lett 1991; 82: 83-90.

11. Stanley J, Goldsworthy M, Threlfall EJ. Molecular phylogenetic typing of pandemic isolates of Salmonella enteritidis. FEMS Microbiol Lett 1992; 90: 153-160.

12. Stanley J, Burnens AP, Threlfall EJ, Chowdry N, Goldsworthy M. Genetic relationships among strains of Salmonella enteritidis in a national epidemic in Switzerland. Epidemiol Infect 1992; 108: 213-220.

13. Helmuth R, Montenegro MA, Steinbeck A, Seiler A, Pietzsch O. Molekularbiologische Metoden zur epidemiologischen Feincharakterisierung von Krankheitserregern am Beispiel von Salmonella enteritidis aus Geflügel. Berl Münch Tierärztl Wochenschr 1990; 103: 416-421.

14. Grimont F, Grimont PAD. Ribosomal ribonucleic acid gene restriction patterns as potential taxonomic tools. Ann Inst Past/Microbiol 1986; 136B: 165-175.

15. Schwartz DC, Saffran W, Welsh J, Haas R, Goldenberg M, Cantor CR. New techniques for purifying large DNAs and studying their properties and packaging. Cold Spring Harb Symp Quant Biol 1983; 47: 189-195.

16. Tompkins LS, Troup N, Labigne-Russel A, Cohen ML. Cloned, random chromosomal sequences as probes to identify Salmonella species. J Infect Dis 1986; 154: 156-162.

17. Baggesen DL, Brown DJ, Gaarslev K, Hansen HC, Bisgaard M. Characterization of Danish isolates of Salmonella enterica serovar Enteritidis by phage typing plasmid profiling. Comparison of isolates obtained from man and broilers. In: Abstracts of International Meeting on Salmonella and Salmonellosis. Ploufragan/Saint-Brieuc, France. September 1992

18. Maniatis T, Fritsch EF, Sambrook J. Molecular cloning, a laboratory manual. Cold Spring Harbor, NY, Cold Spring Harbour Laboratory. 1982.

19. Christensen JP, Olsen JE, Bisgaard M. Ribotypes of Salmonella enterica serotype Gallinarum biovar pullorum and biovar gallinarum. Avian Pathol (in press).

20. Olsen JE, Brown DJ, Baggesen DL, Bisgaard M. Biochemical and molecular characterization of Salmonella enterica serotype berta and comparison of methods for typing. Epidemiol Infect 1992; 108: 243-260.

21. Rossen L, Holmstrøm K, Olsen JE, Rasmussen OF. A rapid polymerase chain reaction (PCR)-based assay for the identification of Listeria monocytogenes in food samples. Int J Food Microbiol 1991; 14: 145-152

22. Feinberg AP, Vogelstein B. A technique for radiolabelling DNA restriction endonuclease fragments to high specific activity. Anal Biochem 1983; 132: 6-13.

23. Chart H, Threlfall EJ, Rowe B. Virulence of Salmonella enteritidis phage type 4 is related to the possession of a 38 MDa plasmid. FEMS Microbiol Lett 1989; 58: 299-304.

24. Stanley J, Chowdry N, Powell N, Threlfall EJ. Chromosomal genotypes (evolutionary lines) of Salmonella berta. FEMS Microbiol Lett 1992; 95 : 247-252.

25. Stanley J, Burnens A, Powell N, Chowdry N, Jones C. The insertion sequence IS200 fingerprints chromosomal genotypes and epidemiological relationships in Salmonella heidelberg. J Gen Microbiol 1992; 138: 2329-2336.

26. Chowdry N, Threlfall EJ, Rowe B, Stanley J. Genotype analysis of faecal and blood isolates of Salmonella dublin from humans in England and Wales. Epidemiol Infect 1993; 110: 217-225.

27. Otal I, Martín C, Vincent-Lévy-Frebault V, Thierry D, Gicquel B. Restriction fragment length polymorphism analysis using IS6110 as an epidemiological marker in tuberculosis. $J$ Clin Microbiol 1991; 29: 1252-1254.

28. Martinetti G, Altwegg M. rRNA gene restriction patterns and plasmid analysis as a tool for typing Salmonella enteritidis. Res Microbiol 1990; 141: 1151-1162.

29. Altwegg M, Hickman-Brenner FW, Farmer JJ. Ribosomal RNA gene restriction patterns provide increased sensitivity for typing Salmonella typhi strains. J Infect Dis 1989; 160: 145-149.

30. Nastasi A, Mammina C, Villafrate MR. rDNA fingerprinting as a tool in epidemiological analysis of Salmonella typhi infections. Epidemiol Infect 1991; 107: 565-576.

31. Frost JA, Ward LR, Rowe B. Acquisition of a drug resistance plasmid converts Salmonella enteritidis phage type 4 to phage type 24. Epidemiol Infect 1989; 103: 243-248.

32. Threlfall EJ, Chart H, Ward LR, de Sa JDH, Rowe B. Interrelationships between strains of Salmonella enteritidis phage types $4,7,7 \mathrm{a}, 8,13,13 \mathrm{a}, 23,24$ and $30 . J \mathrm{Appl}$ Bacteriol 1993; 75: 43-48.

33. Böhm H, Karch H. DNA fingerprinting of Escherichia coli O157:H7 strains by pulsed-field gel electrophoresis. $J$ Clin Microbiol 1992; 30: 2169-2172.

34. Herrmann JL, Bellenger E, Perolat P, Baranton G, Saint Girons I. Pulsed-field gel electrophoresis of Not I digests of leptospiral DNA: a new rapid method of serotype identification. J Clin Microbiol 1992; 30: 1696-1702.

35. Goering RV, Duensing TD. Rapid field inversion gel electrophoresis in combination with an rRNA gene probe in the epidemiological evaluation of staphylococci. $J$ Clin Microbiol $1990 ; 28$ : 426-429.

36. Schoonmaker D, Heimberberger T, Birkhead G. Comparison of ribotyping and restriction enzyme analysis using pulsedfield gel electrophoresis for distinguishing Legionella pneumophila isolates obtained during a nosocomial outbreak. J Clin Microbiol 1992; 30: 1491-1498.

37. Salama SM, Tabor H, Richter M, Taylor DE. Pulsed-field gel electrophoresis for epidemiologic studies of Campylobacter hyointestinalis isolates. $J$ Clin Microbiol 1992; 30: 1982-1984.

38. Rodrigue DC, Cameron DN, Puhr ND et al. Comparison of plasmid profiles, phage types, and antimicrobial resistance patterns of Salmonella enteritidis isolates in the United States. J Clin Microbiol 1992; 30: 854-857.

39. Chart H, Rowe B, Threlfall EJ, Ward LR. Conversion of Salmonella enteritidis phage type 4 to phage type 7 involves loss of lipopolysaccharide with concomitant loss of virulence. FEMS Microbiol Lett 1989; 60: 37-40. 